\title{
PTTG1 expression is associated with hyperproliferative disease and poor prognosis in multiple myeloma
}

Jacqueline E. Noll', Kate Vandyke ${ }^{1,2}$, Duncan R. Hewett ${ }^{1}$, Krzysztof M. Mrozik', Rachel J. Bala', Sharon A. Williams ${ }^{1}$, Chung H. Kok ${ }^{3}$ and Andrew CW Zannettino ${ }^{1,4^{*}}$

\begin{abstract}
Background: Multiple myeloma (MM) is an incurable haematological malignancy characterised by the clonal proliferation of malignant plasma cells within the bone marrow. We have previously identified pituitary tumour transforming gene 1 (Pttg1) as a gene that is significantly upregulated in the haematopoietic compartment of the myeloma-susceptible C57BL/KaLwRij mouse strain, when compared with the myeloma-resistant C57BL/6 mouse. Over-expression of PTTG1 has previously been associated with malignant progression and an enhanced proliferative capacity in solid tumours.
\end{abstract}

Methods: In this study, we investigated PTTG1 gene and protein expression in MM plasma cells from newly diagnosed MM patients. Gene expression profiling was used to identify gene signatures associated with high PTTG1 expression in MM patients. Additionally, we investigated the effect of short hairpin ribonucleic acid (shRNA)-mediated PTTG1 knockdown on the proliferation of the murine myeloma plasma cell line 5TGM1 in vitro and in vivo.

Results: PTTG1 was found to be over-expressed in 36-70\% of MM patients, relative to normal controls, with high PTTG1 expression being associated with poor patient outcomes (hazard ratio 2.49; 95 \% Cl 1.28 to 4.86; $p=0.0075$; log-rank test). In addition, patients with high PTTG1 expression exhibited increased expression of cell proliferation-associated genes including CCNB1, CCNB2, CDK1, AURKA, BIRC5 and DEPDC1. Knockdown of Pttg1 in 5TGM1 cells decreased cellular proliferation, without affecting cell cycle distribution or viability, and decreased expression of Ccnb1, Birc5 and Depdc1 in vitro. Notably, Pttg1 knockdown significantly reduced MM tumour development in vivo, with an $83.2 \%$ reduction in tumour burden at 4 weeks ( $p<0.0001$, two-way ANOVA).

Conclusions: This study supports a role for increased PTTG1 expression in augmenting tumour development in a subset of MM patients.

Keywords: PTTG1, Multiple myeloma, Proliferation, C57BL/KaLwRij

\footnotetext{
* Correspondence: Andrew.Zannettino@adelaide.edu.au Jacqueline E. Noll and Kate Vandyke equal first author.

${ }^{1}$ Myeloma Research Laboratory, Department of Physiology, School of

Medicine, Faculty of Health Sciences, University of Adelaide and Cancer

Theme, South Australian Health and Medical Research Institute (SAHMRI),

Adelaide, Australia

${ }^{4}$ Discipline of Physiology, School of Medicine, Faculty of Health Sciences,

University of Adelaide, Cancer Theme, Level 5 South, SAHMRI, PO Box 11060,

Adelaide, SA 5001, Australia

Full list of author information is available at the end of the article
}

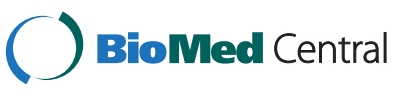

(c) 2015 Noll et al. Open Access This article is distributed under the terms of the Creative Commons Attribution 4.0 International License (http://creativecommons.org/licenses/by/4.0/, which permits unrestricted use, distribution, and reproduction in any medium, provided you give appropriate credit to the original author(s) and the source, provide a link to the Creative Commons license, and indicate if changes were made. The Creative Commons Public Domain Dedication waiver (http://creativecommons.org/publicdomain/zero/1.0/) applies to the data made available in this article, unless otherwise stated. 


\section{Background}

Multiple myeloma (MM) is characterised by the clonal proliferation of malignant plasma cells within the bone marrow (BM) and is the second most common haematological malignancy. The key clinical manifestations of MM include the development of painful osteolytic bone lesions, renal insufficiency, suppressed haematopoietic function and increased BM angiogenesis [1]. There are an array of clinical variants of the disease, ranging from the asymptomatic monoclonal gammopathy of undetermined significance (MGUS) and smouldering MM, to the more aggressive active MM and plasma cell leukaemia. Numerous genes, pathways and miRNAs have been identified in MM that function as predictive biomarkers of highly proliferative disease and likelihood of response to treatment [2-6]. Although the introduction of novel therapies has seen a significant improvement in the median survival of some groups of MM patients, the survival for some subgroups of patients, particularly those with highly proliferative disease, remains poor [7]. This highlights the need to identify new genes and pathways that may be involved in the pathophysiology of MM to aid in both prognosis and the development of novel therapeutics.

The C57BL/KaLwRij (KaLwRij) mouse strain, a closely related derivative of the $\mathrm{C} 57 \mathrm{BL} / 6$ strain, is one of the best-studied pre-clinical animal models of MM. The KaLwRij strain is susceptible to developing benign monoclonal gammopathy and, in a small proportion of mice, $\mathrm{MM}$ at $>2$ years of age $[8,9]$. Additionally, KaLwRij mice exhibit an inherent ability to support the growth of exogenous malignant plasma cells. The intravenous injection of murine myeloma cell lines, such as the KaLwRij-derived lines 5T33MM, 5T2MM and 5TGM1, into KaLwRij mice results in a myeloma-like disease that closely resembles human MM [10-14]. The mechanisms responsible for this susceptibility to the development of myeloma in this strain of mice remain largely unknown. Importantly, we $[15,16]$ and others [17] have previously utilised this model to identify key genes whose expression may play a role in the development of MM disease in these mice.

We have previously identified pituitary tumour transforming gene 1 (Pttg1) (also known as securin, EAP1 and TUTR1) as a gene that displays significantly increased expression in KaLwRij mice compared with C57BL/6 controls [15]. Notably, PTTG1 is over-expressed in a vast array of malignancies including pituitary $[18,19]$, colorectal [20], thyroid [21] and lung [22] cancer, and high levels of PTTG1 are commonly associated with an enhanced proliferative capacity, increased tumour grade and high invasive potential [23]. PTTG1 is a key regulator of sister chromatid segregation during mitosis and, additionally, is involved in DNA damage repair [23]. An increase in PTTG1 expression has previously been described in up to $63 \%$ of MM patients [24, 25]; however, the role played by PTTG1 in MM disease development has not been determined. In the present study, we confirm up-regulation of PTTG1 in MM plasma cells from a subset of MM patients compared with both MGUS and healthy controls and show that elevated PTTG1 expression is associated with an increase in cell cycle-related gene expression and is associated with poor survival. Furthermore, knockdown of Pttg1 decreases cellular proliferation in vitro and reduces myeloma tumour burden in vivo in the KaLwRij model of MM. Collectively, these data support a role for PTTG1 in promoting MM disease pathogenesis, likely through cell cycle- and proliferation-related pathways.

\section{Results}

\section{PTTG1 is over-expressed in the C57BL/KaLwRij mouse model of myeloma}

In order to identify genes that may play a role in the development of myeloma, we previously compared the transcriptome of the bone/BM of KaLwRij mice to that of the genetically related C57BL/6 strain using microarray [15]. Using this approach, we identified Pttg1 as a gene with significantly increased expression (2.9-fold; $p=0.00037$, LIMMA) within the bone/BM of KaLwRij mice compared with C57BL/6 controls [15]. Quantitative real-time PCR (qRT-PCR) was subsequently used to assess the relative messenger ribonucleic acid (mRNA) expression levels of Pttg1 in a range of tissues derived from the C57BL/6 and KaLwRij mice $(n=3 /$ group). As seen in Fig. 1a, Pttg1 mRNA levels were significantly increased in the bone, BM, peripheral blood and spleen of KaLwRij mice, when compared with those of C57BL/ 6 controls $(p<0.05, t$ test). Although an increase in Pttg1 expression was also noted in the thymus, this did not reach significance ( $p=0.11, t$ test). Furthermore, there was a significant increase in Pttg1 expression in $\mathrm{CD} 138^{+}$plasma cells derived from KaLwRij mice compared with those from C57BL/6 controls (Fig. $1 \mathrm{~b} ; p=0.045, t$ test). Together, these data confirm that Pttg1 expression levels are up-regulated in the bone, haematopoietic tissues and plasma cells of KaLwRij mice.

PTTG1 is over-expressed in MM patients and is associated with poor survival

To examine whether MM patients display increased PTTG1 expression, we performed in silico analyses in three independent publically available microarray datasets (E-GEOD-6477; E-GEOD-16122; E-MTAB-363) comparing the gene expression profiles of $\mathrm{CD} 138^{+}$-isolated plasma cells from newly diagnosed MGUS and $\mathrm{MM}$ patients and normal controls. In E-GEOD-6477 and E-MTAB-363, PTTG1 expression was significantly increased in the MM patient cohort compared with the normal controls $(p<0.05)$ and MGUS patients $(p<0.05$; 


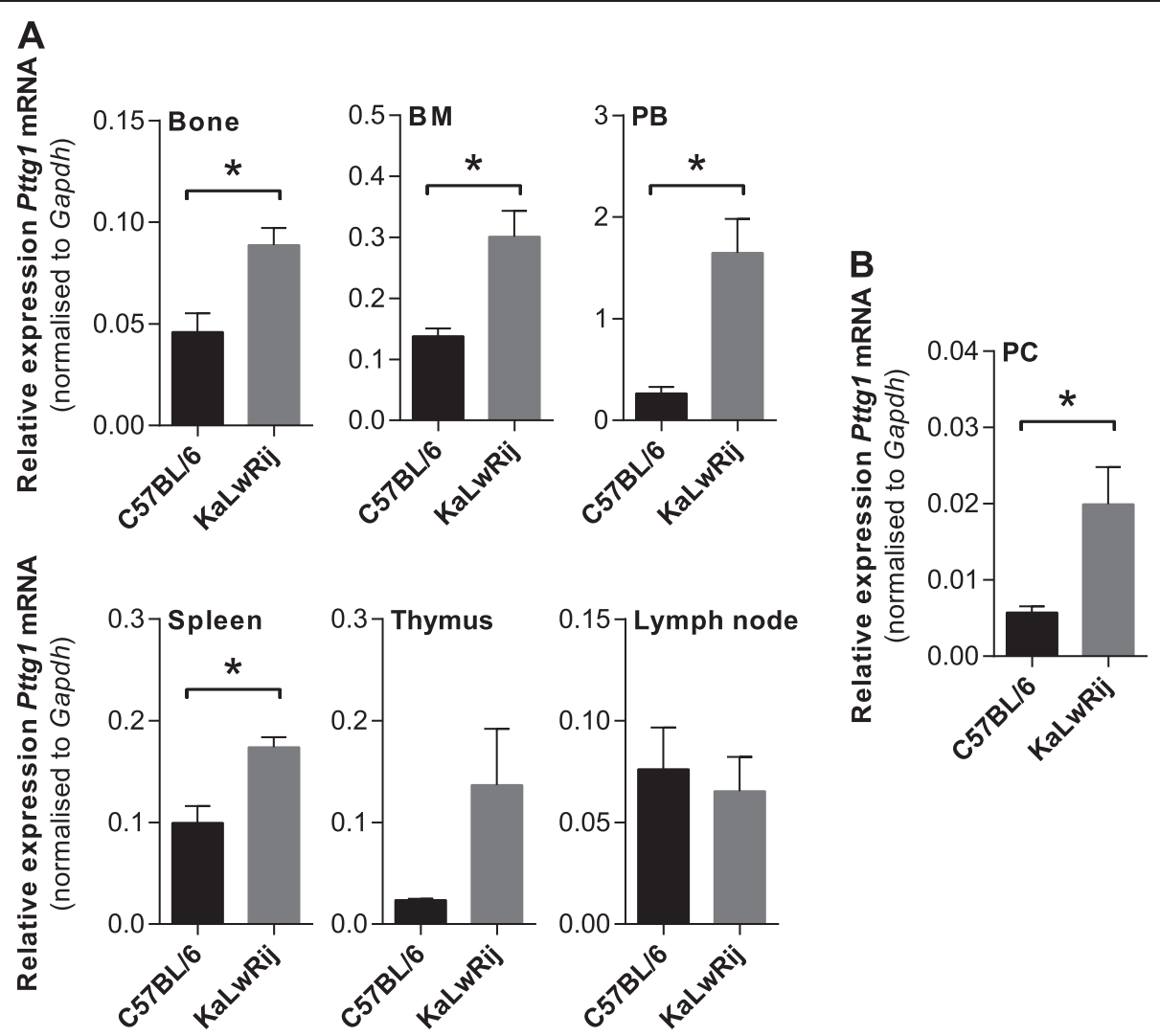

Fig. 1 Pttg1 expression is increased in haematopoietic tissues of C57BL/KaLwRij mice. a Bone, bone marrow (BM), peripheral blood (PB), spleen and thymus and combined popliteal, inguinal and axillary lymph node tissues were isolated from C57BL/6 and C57BL/KaLwRij mice ( $n=3 / \mathrm{group}$ ) and total RNA extracted. Pttg1 mRNA expression was determined by qRT-PCR analysis. ${ }^{*} p<0.05, t$ test. $\mathbf{b}$ CD $138^{+}$plasma cells (PC) were isolated from the BM of C57BL/6 and C57BL/KaLwRij mice ( $n=3 /$ group). Pttg1 mRNA was significantly increased in KaLwRij-derived plasma cells compared with C57BL/6 controls. Graphs depict mean + SEM; ${ }^{*} p<0.05, t$ test

Fig. 2a, b). In E-GEOD-16122, PTTG1 expression was significantly increased in MM patients compared with MGUS patients $(p<0.05$; Fig. 2c). Approximately 38-70 \% (38.4 \% [28/73], E-GEOD-6477; $70.3 \%$ [109/155], EMTAB-363; 68.4 \% [66/133], E-GEOD-16122) of MM patients expressed PTTG1 at levels higher than the normal range (mean $+2 \mathrm{SD}$ of the normal cohort expression). We subsequently isolated $\mathrm{CD}_{138^{+}}$plasma cells from diagnostic MM patient BM $(n=11)$ using CD138-MACS, total RNA was isolated and PTTG1 mRNA expression examined by qRT-PCR. Four of the 11 patients $(36.4 \%)$ were found to express PTTG1 in the purified plasma cells (Additional file 1: Figure S1). Using dual-colour immunohistochemistry, we also confirmed PTTG1 protein expression within $\mathrm{CD} 138^{+}$plasma cells in BM trephines from two PTTG1-expressing MM patients (Fig. 2d). Consistent with previous reports [24, 26], PTTG1 protein was predominantly cytoplasmic.

Collectively, these data suggest that over-expression of PTTG1 is a feature of MM disease in approximately $36-70 \%$ of MM patients. In order to determine whether the increased expression of PTTG1 in MM patients was related to patient survival, newly diagnosed MM patients enrolled in the total therapy 2 (TT2) trial, from publically available microarray dataset GSE4581, were stratified based on PTTG1 expression levels. The quartile with the highest PTTG1 expression was classified as PTTG1 high ( $n=71$ patients), while the remaining patients $(n=214)$ were classified as PTTG1 low. Subsequent analysis of overall survival identified a significantly poorer survival in the PTTG1 high group (hazard ratio 2.49 ; $95 \%$ CI 1.28 to $4.86 ; p=0.0075$; logrank [Mantel-Cox] test; Fig. 2e).

When MM patients in dataset GSE4581 were partitioned into gene expression profiling-defined subgroups (UAMS classifications) [4], elevated PTTG1 was found to be associated with specific disease subtypes (Fig. 2f). Specifically, PTTG1 expression was elevated in the PR subgroup, characterised by expression of proliferation-related genes, when compared with the subgroups characterised by chromosomal translocations involving cyclin D1 and D3 (CD1 and CD2), MAF 


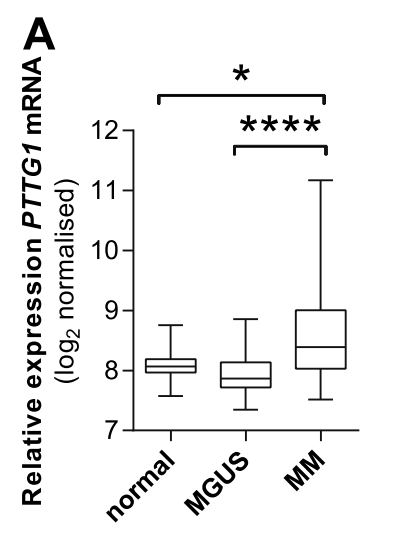

D

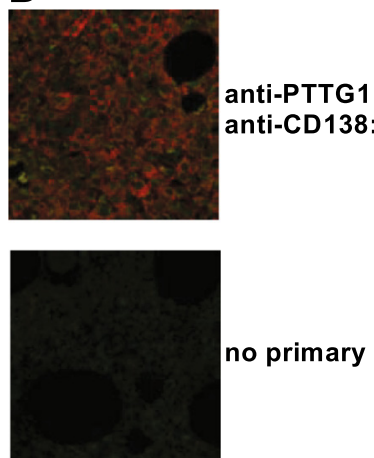

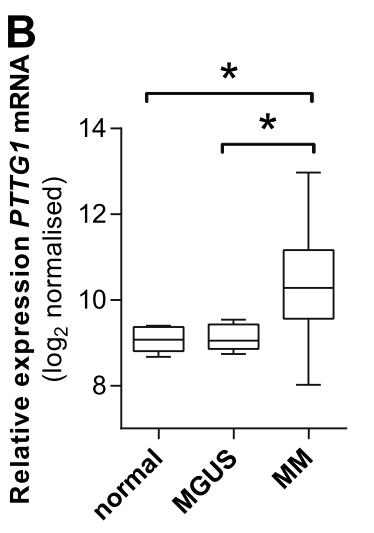

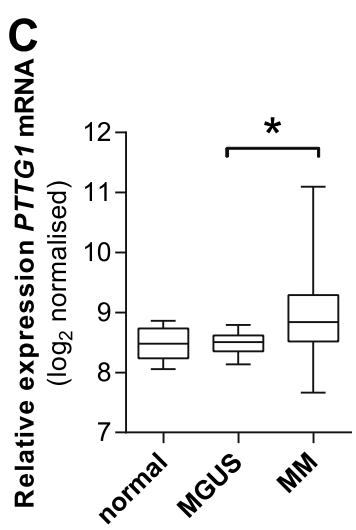

E

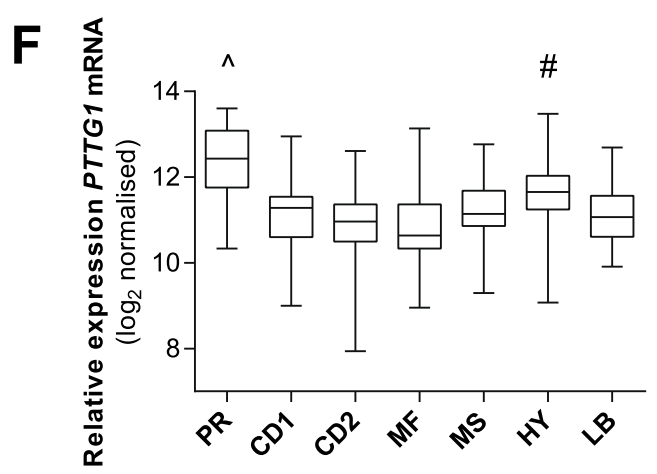

Fig. 2 PTTG1 is over-expressed in MM patients. In silico analysis was performed on publically available gene expression datasets from CD138 plasma cells isolated by MACS from MM $(n=73)$ and MGUS $(n=22)$ patients and healthy controls $(n=15)$ (E-GEOD-6477) $(\mathbf{a})$, MM $(n=155)$ and MGUS $(n=5)$ patients and healthy controls $(n=5)(E-M T A B-363)(\mathbf{b})$ and MM $(n=133)$ and MGUS $(n=11)$ patients and healthy controls $(n=5)(E-G E O D-16122)$ (c). Box and whiskers plots show the median and interquartile ranges for each cohort. ${ }^{*} p<0.05$; ${ }^{* * *} p<0.0001$; Kruskal-Wallis test with Dunn's multiple comparison tests. $\mathbf{d}$ Representative image of a BM trephine section from an MM patient stained with anti-CD138 (red) and anti-PTTG1 (green), showing plasma cell-specific protein expression of PTTG1. A negative (no primary antibody) control is shown. e Kaplan-Meier plot of PTTG1 high patients (quartile $4 ; n=71$ ) vS PTTG1 low patients (quartiles $1-3 ; n=214)$ (TT2 patients from GSE4581). f MM patients from GSE4581 $(n=414)$ were stratified into subgroups based on the UAMS criteria; namely, patients characterised by increased proliferation-related genes (PR), chromosomal translocations involving cyclin D1 and cyclin D3 (CD1 and CD2), MAF (MF) or MMSET (MS), as well as patients exhibiting hyperdiploidy (HY) and decreased prevalence of lytic bone disease (LB) [4]. The expression of PTTG1 was analysed in each subset. Box and whiskers plots show the median and interquartile ranges for each cohort; $\wedge p<0.0001$ relative to CD1, CD2, MF, MS, HY and LB; \#p<0.01 relative to CD2, MF, MS, LB; Kruskal-Wallis test with Dunn's multiple comparison tests

(MF) or MMSET (MS), by hyperdiploidy (HY) or by a decreased prevalence of lytic bone disease (LB) (Fig. 2f). Additionally, significantly elevated PTTG1 was observed in the HY group, when compared with the CD2, LB, MF and MS subgroups.
PTTG1 expression in MM patients is associated with an increase in expression of cell cycle-associated genes

As elevated PTTG1 expression was shown to be associated with poor outcomes in MM patients, we next compared MM plasma cell gene expression between PTTG1 
high and PTTG1 low MM patients in four independent microarray datasets. Twenty-nine genes were found to be significantly down-regulated, and 1459 genes significantly up-regulated (excluding PTTG1) in at least one dataset (Fisher's $p$ value $<0.05$ ). Of these, 155 genes were significantly up-regulated, and no genes were downregulated, in all four datasets. Of the 119 of these genes that were classified in DAVID, there was an enrichment for cell cycle-related genes, with 82/119 (68.9 \%) being genes associated with mitosis. Genes up-regulated by more than twofold, all with a strong $(p<0.0001)$ positive correlation (Spearman) with PTTG1 expression, included key cell cycle regulators (eg. CCNB1, CCNB2, CDK1, $C K S 2$ ), genes associated with DNA replication (eg. MCM2, GINS1, RRM2), response to DNA damage (eg. CHEK1, PBK), mitotic spindle and microtubule organisation (eg. AURKA, NEK1, PRC1), chromosome segregation during mitosis (eg. CENPA, CENPH, PENPK, BIRC5) and ubiquitin ligase activity and protein catabolism (eg. UBE2C, CDC20, MAD2L1, DTL) (Table 1; Fig. 3). Other non-cell cycle genes associated with high PTTG1 include $D E P D C 1$ and the histone demethylase EZH2.

\section{Pttg1 knockdown in 5TGM1 cells inhibits cell proliferation in vitro}

Consistent with the elevated expression of Pttg1 in KaLwRij-derived plasma cells and the KaLwRij mouse tumour origin of the 5TGM1 cell line [27, 28], 5TGM1 cells express high levels of Pttg1 (data not shown). Using lentiviral transduction, we stably introduced a short hairpin ribonucleic acid (shRNA) within an mCherry-tagged vector to specifically knockdown Pttg1 in luciferase-expressing 5TGM1 cells. Pttg1 expression levels, as assessed by qRT-PCR (Fig. 4a) and Western blot (Fig. 4b), were reduced by $70 \%$ in the knockdown cell line (denoted 5TGM1-PTTG-kd) when compared with a scrambled shRNA control line (5TGM1-SCRAM). These cell lines were used for subsequent in vivo and in vitro experiments.

As high PTTG1 expression in MM patients correlates with increased expression of cell cycle- and proliferationassociated genes, we next examined whether Pttg1 may play a role in modulating cell cycle progression and proliferation in murine myeloma plasma cells. After 3 days of culture, cell number, as determined by water-soluble tetrazolium salt (WST-1) assay, was significantly decreased by $75 \%$ in the 5TGM1-PTTG-kd cells when compared with the 5TGM1-SCRAM controls (Fig. 4c, $p<0.01$, two-way ANOVA with Sidak's multiple comparison tests). Furthermore, the proliferative capacity of the 5TGM1-PTTG-kd line in vitro was decreased by $83 \%$ compared with the 5TGM1-SCRAM control, as determined by bromodeoxyuridine (BrdU) incorporation over $2 \mathrm{~h}$ (Fig. $4 \mathrm{~d}, p=0.018$, $t$ test). However, there was no effect of Pttg1 knockdown on cell cycle distribution, as determined by propidium iodide (PI) staining (Fig. 4e, $p=0.998$, two-way ANOVA). Furthermore, cell viability, as assessed by trypan blue exclusion, was not affected by Pttg1 knockdown (data not shown). Taken together, these results suggest that elevated expression of Pttg1 in the malignant 5TGM1 cells may be associated with increased cell proliferation.

\section{Pttg1 knockdown reduces the expression of proliferation-} related genes in the 5TGM1 mouse myeloma cell line In order to elucidate a potential mechanism through which loss of Pttg1 inhibits proliferation, we examined the expression of a selection of proliferation-related genes identified in the human patient datasets (see Table 1) in the 5TGM1-PTTG1-kd cell line compared with the 5TGM1-SCRAM control. Our findings show that expression of genes encoding the cell cycle regulator Ccnb1 ( $p=0.0039, t$ test) and the kinetochore-associated protein $\operatorname{Birc} 5$ ( $p=0.0008, t$ test) were decreased by 52 and $48 \%$, respectively, in the PTTG1-kd cells, compared with the scramble control cells (Fig. 5). In contrast, expression of genes encoding the cell cycle regulator $C d k 1$ and the deoxyribonucleotide synthesis enzyme Rrm2 were not affected by Pttg1 knockdown $(p=0.2391, t$ test). Additionally, expression of Depdc1, which has previously been implicated in MM [29], was decreased by $38 \%$ $(p=0.0055, t$ test $)$ in the PTTG1-kd cells.

\section{Pttg1 knockdown in 5TGM1 cells reduces tumour burden in vivo}

To ascertain whether the observed decrease in proliferation in the 5TGM1-PTTG-kd cells corresponded with reduced tumour growth in vivo, the 5TGM1-PTTG-kd and 5TGM1-SCRAM cell lines were injected i.v. into C57BL/KaLwRij mice and tumour burden was monitored at weekly intervals by bioluminescent imaging. As seen in Fig. 6, tumour burden was decreased by $83 \%$ in the Pttg1 knockdown group compared with the control group at 4 weeks $(p<0.0001$, two-way ANOVA with Sidak's post-test), suggesting that high basal expression of Pttg1 in 5TGM1 cells is important for in vivo tumour growth.

\section{Discussion}

Over-expression of PTTG1 has previously been linked to neoplastic transformation in a wide range of cell types [23, 30-32]. Increased expression of PTTG1 has been extensively studied in pituitary adenomas, as well as a range of other endocrine cancers (reviewed by [33]). By comparison, little is known about the role PTTG1 may play in haematological malignancies. Early studies demonstrated that PTTG1 was highly expressed in approximately $70 \%$ of patients with leukaemia, lymphoma or other myelodysplastic diseases but not in healthy donors 
Table 1 Gene significantly upregulated more than twofold in PTTG1 high MM patients

\begin{tabular}{|c|c|c|c|}
\hline Probeset ID & Gene symbol & Fisher's $p$ value $^{b}$ & Fold change $^{c}$ [mean $\left.(95 \% \mathrm{Cl})\right]$ \\
\hline \multicolumn{4}{|c|}{ Regulation Of cell cycle } \\
\hline 213226_at & CCNA2 & $2.20 \times 10^{-31}$ & $2.32(1.84-2.80)$ \\
\hline 214710_s_at & CCNB1 & $2.18 \times 10^{-40}$ & $4.07(2.61-5.53)$ \\
\hline 202705_at & CCNB2 & $1.98 \times 10^{-41}$ & $3.54(1.93-5.14)$ \\
\hline 203213_at & CDK1 & $9.11 \times 10^{-37}$ & $3.91(2.44-5.39)$ \\
\hline 1555758_a_at & CDKN3 & $1.63 \times 10^{-40}$ & $2.90(1.68-4.13)$ \\
\hline 204170_s_at & CKS2 & $2.02 \times 10^{-35}$ & $2.88(2.69-3.07)$ \\
\hline 218350_s_at & GMNN & $1.03 \times 10^{-32}$ & $2.32(1.71-2.93)$ \\
\hline 204825_at & MELK & $5.20 \times 10^{-35}$ & $2.67(1.88-3.47)$ \\
\hline \multicolumn{4}{|l|}{ DNA replication } \\
\hline 206102_at & GINS1 & $6.74 \times 10^{-29}$ & $2.99(1.91-4.07)$ \\
\hline 202107_s_at & MCM2 & $1.04 \times 10^{-33}$ & $2.33(1.79-2.87)$ \\
\hline 201930_at & MCM6 & $5.41 \times 10^{-20}$ & $2.03(1.32-2.74)$ \\
\hline 201202_at & PCNA & $1.74 \times 10^{-22}$ & $2.36(1.81-2.91)$ \\
\hline 204127_at & RFC3 & $3.82 \times 10^{-17}$ & $2.12(1.27-2.97)$ \\
\hline 209773_s_at & RRM2 & $2.80 \times 10^{-36}$ & $4.15(2.38-5.92)$ \\
\hline 1554696_s_at & TYMS & $7.15 \times 10^{-41}$ & $2.47(0.95-4.00)$ \\
\hline \multicolumn{4}{|c|}{ Response to DNA damage } \\
\hline 205394_at & CHEK1 & $1.33 \times 10^{-36}$ & $2.74(1.88-3.61)$ \\
\hline 213007_at & FANCI & $2.04 \times 10^{-24}$ & $2.25(1.04-3.47)$ \\
\hline 202503_s_at & KIAA0101 & $1.34 \times 10^{-38}$ & $3.59(2.23-4.96)$ \\
\hline 223700_at & MND1 & $9.45 \times 10^{-41}$ & $2.03(1.44-2.92)$ \\
\hline 219148_at & PBK & $3.18 \times 10^{-38}$ & $3.62(1.60-5.64)$ \\
\hline 205909_at & POLE2 & $5.33 \times 10^{-25}$ & $2.08(1.49-2.67)$ \\
\hline 204146_at & RAD51AP1 & $2.74 \times 10^{-26}$ & $2.41(1.56-3.26)$ \\
\hline 219258_at & TIPIN & $2.66 \times 10^{-33}$ & $2.06(1.70-2.41)$ \\
\hline 204033_at & TRIP13 & $4.71 \times 10^{-38}$ & $2.45(1.87-3.04)$ \\
\hline \multicolumn{4}{|c|}{ Mitotic spindle and microtubule organisation } \\
\hline 208079_s_at & AURKA & $4.49 \times 10^{-35}$ & $2.74(2.22-3.26)$ \\
\hline 204162_at & NDC80 & $1.96 \times 10^{-32}$ & $3.23(1.85-4.62)$ \\
\hline 204641_at & NEK2 & $1.24 \times 10^{-29}$ & $2.84(1.65-4.03)$ \\
\hline 218039_at & NUSAP1 & $9.20 \times 10^{-37}$ & $3.47(1.29-5.66)$ \\
\hline 218009_s_at & $P R C 1$ & $4.37 \times 10^{-31}$ & $2.54(1.69-3.39)$ \\
\hline 222077_s_at & RACGAP1 & $5.24 \times 10^{-31}$ & $3.01(1.90-4.13)$ \\
\hline 209891_at & SPC25 & $3.04 \times 10^{-40}$ & $2.84(2.62-3.06)$ \\
\hline 200783_s_at & STMN1 & $1.27 \times 10^{-34}$ & $2.33(1.73-2.94)$ \\
\hline 204822_at & TTK & $1.30 \times 10^{-34}$ & $2.66(1.03-4.28)$ \\
\hline 204026_s_at & ZWINT & $4.49 \times 10^{-29}$ & $3.09(1.01-5.17)$ \\
\hline \multicolumn{4}{|c|}{ Sister chromatid segregation } \\
\hline 202095_s_at & BIRC5 & $8.63 \times 10^{-38}$ & $2.60(1.94-3.26)$ \\
\hline 204962_s_at & CENPA & $7.33 \times 10^{-38}$ & $2.97(2.14-3.81)$ \\
\hline 231772_x_at & CENPH & $2.98 \times 10^{-32}$ & $2.12(1.76-2.47)$ \\
\hline 222848_at & CENPK & $5.40 \times 10^{-31}$ & $2.90(1.86-3.94)$ \\
\hline 219555_s_at & CENPN & $1.53 \times 10^{-33}$ & $2.06(1.45-2.67)$ \\
\hline
\end{tabular}


Table 1 Gene significantly upregulated more than twofold in PTTG1 high MM patients (Continued)

\begin{tabular}{|c|c|c|c|}
\hline 226936_at & CENPW & $2.43 \times 10^{-39}$ & $2.40(1.39-3.41)$ \\
\hline 218663_at & NCAPG & $2.21 \times 10^{-34}$ & $2.61(1.44-3.79)$ \\
\hline 213599_at & OIP5 & $6.22 \times 10^{-41}$ & $2.99(2.39-3.59)$ \\
\hline \multicolumn{4}{|c|}{ Ubiquitin ligase activity } \\
\hline 202870_s_at & CDC20 & $1.02 \times 10^{-36}$ & $2.43(2.28-2.58)$ \\
\hline 222680_s_at & DTL & $4.43 \times 10^{-29}$ & $2.88(1.22-4.55)$ \\
\hline 203362_s_at & MAD2L1 & $1.01 \times 10^{-32}$ & $3.07(1.92-4.23)$ \\
\hline 202954_at & UBE2C & $2.48 \times 10^{-37}$ & $2.20(1.15-3.24)$ \\
\hline 223229_at & UBE2T & $4.11 \times 10^{-30}$ & $2.30(0.82-3.78)$ \\
\hline \multicolumn{4}{|c|}{ Chromatin modification } \\
\hline 203358_s_at & $E Z H 2$ & $1.21 \times 10^{-24}$ & $2.41(1.63-3.20)$ \\
\hline 227212_s_at & PHF19 & $1.18 \times 10^{-29}$ & $2.38(1.59-3.17)$ \\
\hline \multicolumn{4}{|l|}{ Other } \\
\hline 222958_s_at & DEPDC1 & $2.47 \times 10^{-25}$ & $2.32(1.31-3.32)$ \\
\hline 226980_at & $D E P D C 1 B$ & $2.52 \times 10^{-33}$ & $2.37(2.00-2.74)$ \\
\hline 225834_at & FAM72A/FAM72B/FAM72C/FAM72D & $1.10 \times 10^{-29}$ & $3.31(1.01-5.62)$ \\
\hline 228069_at & MTFR2 & $1.36 \times 10^{-31}$ & $2.07(1.62-2.53)$ \\
\hline 235113_at & PPIL5 & $3.17 \times 10^{-27}$ & $2.08(1.53-2.63)$ \\
\hline 229551_x_at & ZNF367 & $1.30 \times 10^{-20}$ & $2.20(1.48-2.93)$ \\
\hline
\end{tabular}

${ }^{a}$ Genes are shown for which statistically significant differences were observed in all of the four datasets analysed. Data is shown for the Affymetrix probeset with the lowest $p$ value for each gene

${ }^{\mathrm{b}}$ Fisher's method was used to combine the $p$ values across the four datasets

${ }^{\mathrm{C}}$ Mean fold change observed for PTTG1 high vs PTTG1 low patients across the four datasets

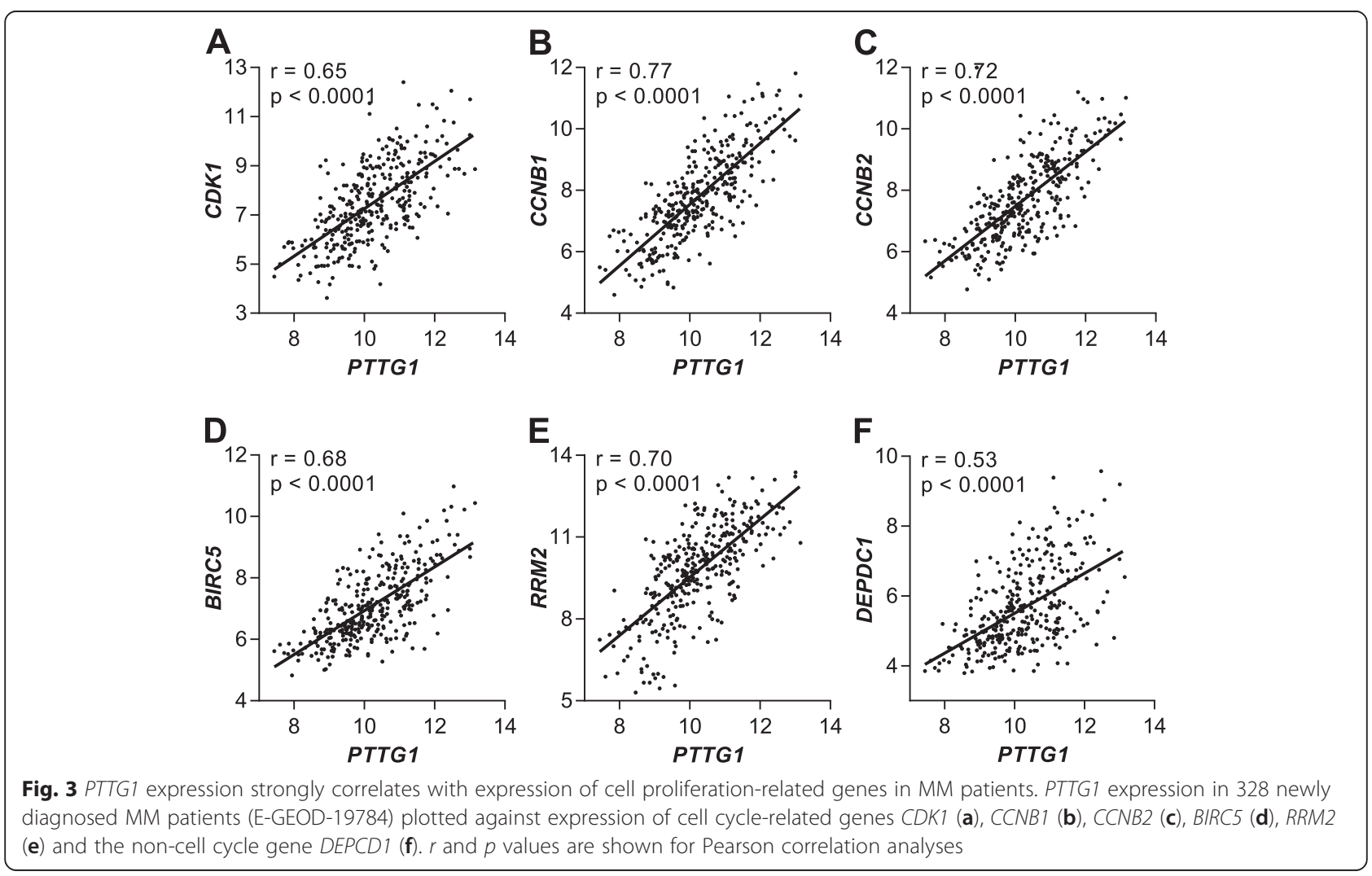



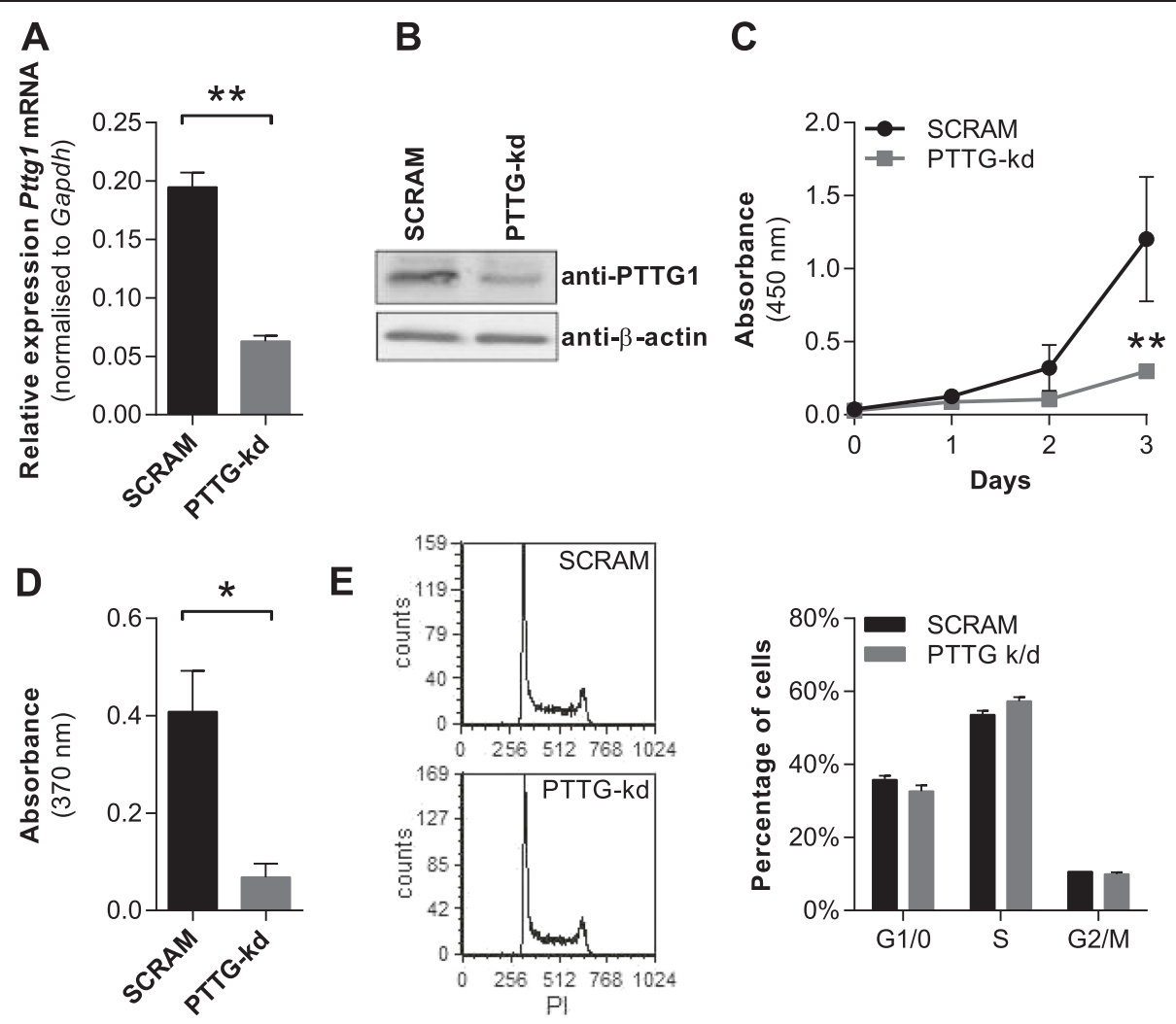

Fig. 4 Pttg1 knockdown reduces 5TGM1 proliferation in vitro. a A 70 \% knockdown of Pttg 1 mRNA was confirmed in 5TGM1-PTTG-kd cells compared with 5TGM1-SCRAM controls by qRT-PCR. $\mathbf{b}$ Reduced protein expression of Pttg1 was confirmed by Western blot. c Cells were seeded at $1 \times 10^{5}$ cells/ $\mathrm{mL}$ in a 96-well plate, and cell numbers over 3 days were quantitated by WST-1 assay, read at $450 \mathrm{~nm}$. $\mathbf{d}$ Cells were seeded at $4 \times 10^{5}$ cells $/ \mathrm{mL}$ in a $96-$ well plate, BrdU substrate was added and BrdU incorporation was quantitated after $2 \mathrm{~h}$ by ELISA, measured by absorbance at $370 \mathrm{~nm}$. ${ }^{*} p<0.05, t$ test. e Cells were seeded at $4 \times 10^{5}$ cells $/ \mathrm{mL}$ in a six-well plate and cultured for $24 \mathrm{~h}$, and cell cycle distribution was assessed following PI staining. Representative FACS plots (PI histograms) are shown. Graphs depict mean + SEM of three independent experiments

[26, 34]. More recently, high PTTG1 protein expression has been observed in $63 \%$ of MM patients [24, 25]; however, the biological and prognostic significance of PTTG1 over-expression was not investigated in these studies. In the current study, we show a significant increase in PTTG1 expression in human MM patients, with approximately $36-70 \%$ of patients showing increased expression of PTTG1 above that seen in healthy controls, findings which were subsequently confirmed by analysis of our own MM patient specimens. Importantly, increased PTTG1 expression was associated with poor overall survival, suggesting that high PTTG1 expression may be implicated in MM disease severity and poor patient outcome. Additionally, our analyses show that PTTG1 is upregulated in MM patients, but not in the asymptomatic precursor MGUS, suggesting an association with disease progression.

Chromosomal rearrangements and duplications are early events in the development of myeloma with the presence of genomic instability being associated with poor prognosis [35]. In this study, elevated PTTG1 was specifically observed in a subgroup of MM patients displaying a hyperdiploid phenotype (HY group). This is consistent with the role of PTTG1 in regulating sister chromatid separation during mitosis $[36,37]$ as dysregulation of this key function commonly leads to genomic instability [38-42]. Over-expression of PTTG1 promotes dysregulated chromosome segregation resulting in aneuploidy in human cancer cell lines [40, 41, 43]. The chromosomal instability induced by PTTG1 over-expression has been proposed as a mechanism whereby PTTG1 drives malignant transformation [44]. Interestingly, gene expression profiling studies have shown that the presence of chromosomal instability in newly diagnosed myeloma patients is associated with a gene expression profile that includes upregulation of PTTG1 [35]. These data suggest that expression of PTTG1 in MM patients may contribute to the development of chromosome duplications characteristic of the HY group.

In addition to its association with hyperdiploidy, we found a significant increase in PTTG1 expression in subset of patients with a proliferation-related gene expression profile (PR group), which is associated with high-risk disease and poor prognosis [4]. Elevated 


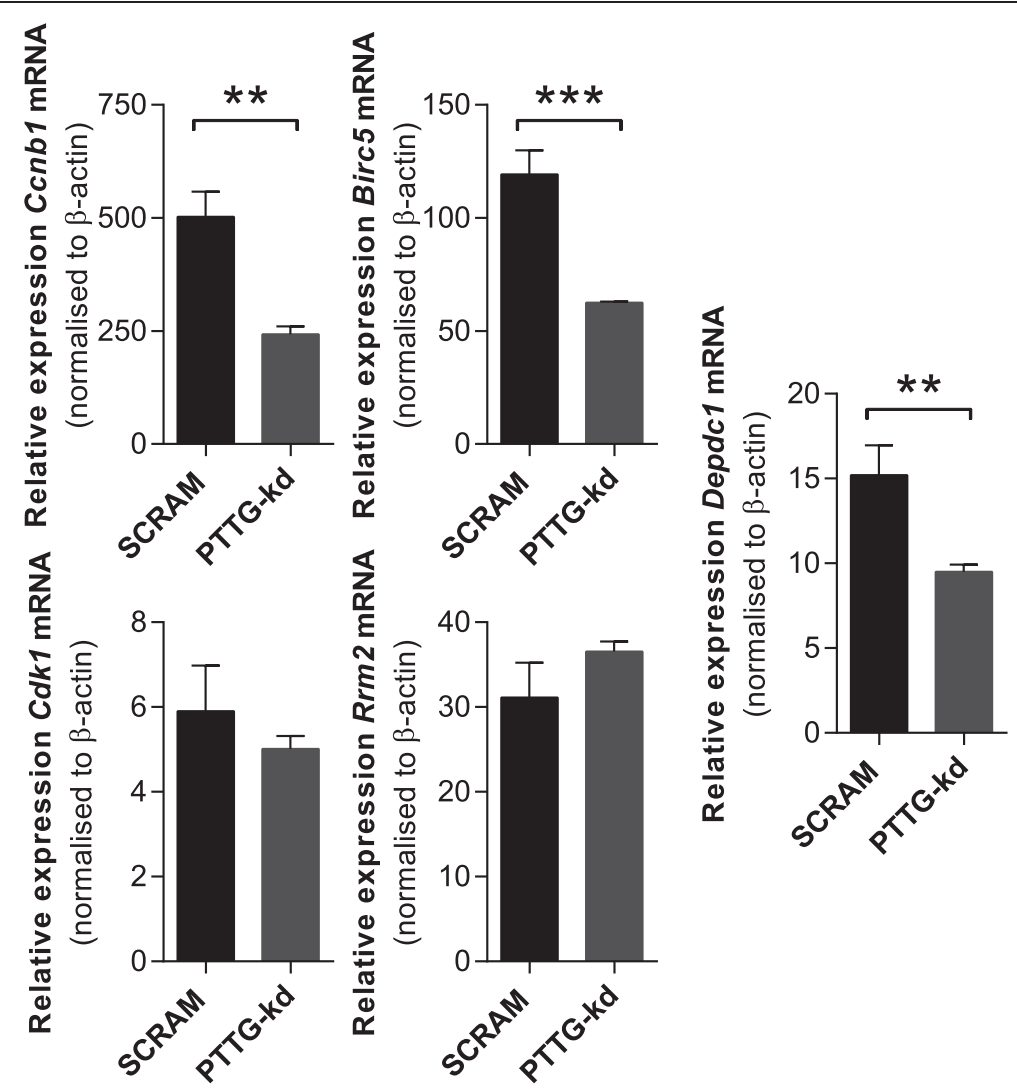

Fig. 5 Pttg1 knockdown results in deregulation of proliferation-related genes in 5TGM1 cells. Expression of Ccnb1, Birc5, Cdk1, Rrm2 and Depcd1 was quantitated in 5TGM1-PTTG-kd cells compared with 5TGM1-SCRAM controls by qRT-PCR. Graphs depict mean + SD of triplicates from a single experiment. ${ }^{*} p<0.05, t$ test

PTTG1 has previously been identified as part of a gene signature that is associated with increased proliferative index and is an independent predictor of poor prognosis in newly diagnosed MM patients [45]. The increase in PTTG1 in MM patients with highly proliferative disease is consistent with data from other systems which show that increased expression of PTTG1 correlates with high levels of cellular proliferation [46-48]. While, in the short term, over-expression of PTTG1 prevents exit from mitosis, leading to cell cycle arrest and increased cell death $[49,50]$, sustained; stable overexpression of PTTG1 generally leads to enhanced
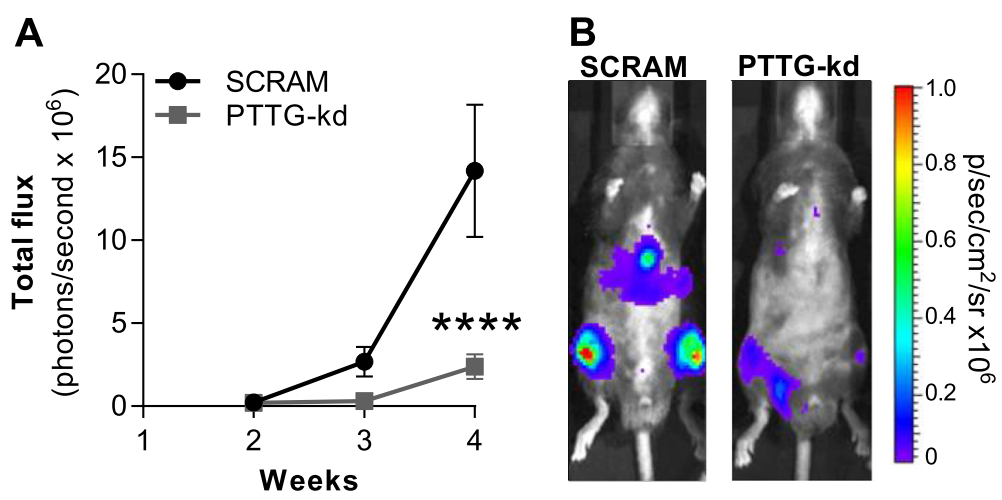

Fig 6 Pttg1 knockdown reduces tumour growth in vivo. a Total tumour burden was measured at 2-, 3- and 4-weeks post-tumour cell inoculation using bioluminescence imaging techniques. A significant reduction in total tumour burden was observed in the Pttg kd group $(n=15)$ compared with SCRAM controls $(n=10)$; ${ }^{* * *} p<0.001$, two-way ANOVA with Sidak's post-test. b Representative bioluminescent images of mice injected with 5TGM1-SCRAM control (left) and 5TGM1-PTTG-kd (right) cells at 4-weeks post-tumour cell inoculation are shown 
cellular proliferation [32, 51, 52]. Notably, our Pttg1 knockdown studies in the KaLwRij-derived 5TGM1 myeloma plasma cell line resulted in a reduction in cellular proliferation in vitro, as well as decreased tumour development in vivo. This is consistent with a number of animal knockout and knockdown studies in a range of different cell types, which show that reduction of PTTG1 expression inhibits cell proliferation [52-59]. Taken together, these data are consistent with increased expression of Pttg1 being a core requirement for the growth of malignant plasma cells in some patients.

In support of the pro-proliferative role of PTTG1 in myeloma, analysis of four independent MM patient gene expression datasets revealed that the majority (68.9 \%) of genes significantly up-regulated in PTTG1 high patients had proliferation-related functions, specifically cell cycle regulation, DNA replication, mitotic spindle formation, chromosome segregation and DNA damage pathways. These included 20 of the top 50 genes originally identified as being upregulated in the PR subgroup [4]. Notable exclusions include the cancer/testis antigens MAGEA1, MAGEA3, MAGEA6, GAGE1, GAGE2, GAGE4 and GAGE5, which were originally identified as being strongly upregulated in the PR subgroup [4] but are not upregulated in our PTTG1 high patients. This, combined with the strength of the association between PTTG1 expression and the expression of cell cycle-associated genes, suggests that the upregulation of proliferation-related genes with high PTTG1 expression is not simply due to an increased representation of PR patients in this group.

Indeed, we found that knockdown of Pttg1 was associated with downregulation of cell cycle regulatory genes in the 5TGM1 cell line, suggesting a potential mechanism for the decreased proliferation observed in these cells. Cell cycle genes CcnB1 (cyclin B1) and Birc5 (survivin), which were among the most highly upregulated genes identified in our patient analysis, were down-regulated by approximately $50 \%$ by Pttg1 knockdown in the 5TGM1 cells. Both CCNB1 and BIRC5 have been identified as part of gene expression signatures predictive of high-risk disease and poor prognosis in MM patients in several studies [4, 5, 45, 60-63]. PTTG1, CCNB1 and BIRC5 expression are under tight transcriptional control during cell cycle progression, being switched on during $\mathrm{G}_{2} / \mathrm{M}$ phase $[46,49,64,65]$. While this suggests that downregulation of $C c n b 1$ and Birc5 expression following Pttg1 could be a consequence of a decrease in $G_{2} / M$ phase cells, we saw no change in cell cycle distribution in the PTTG1-kd cells to support this. Cyclin B1, an essential regulator of cell cycle transition during mitosis, has previously been identified as a PTTG1-regulated gene whose up-regulation is associated with enhanced proliferation in keratinocytes [52]. BIRC5 is an inhibitor of apoptosis proteins (IAP) family member which regulates microtubule dynamics and chromosomal segregation during mitosis. Over-expression and knockdown studies in human myeloma cell lines have implicated BIRC5 in proliferation and protection of MM cells from apoptosis [62, 64, 66]. Taken together, these data suggest a potential role for cyclin B1 and BIRC5 in PTTG1-mediated tumour growth.

In addition to its role as a securin during chromatid segregation, PTTG1 can directly regulate gene expression. PTTG1 has been shown to physically interact with p53, repressing its transcriptional activity [36]. Additionally, p53 expression can be transcriptionally and translationally repressed by transient over-expression of PTTG1 [67]. Notably, some of the genes found to strongly correlate with PTTG1 expression in this study, including CDK1, CCNB1, CCNB2 and BIRC5 are known to be inhibited downstream of p53 [68-70]; p53-mediated regulation of gene expression down stream of PTTG1 could be a focus of future studies. However, we found no correlation between PTTG1 and p53 expression in MM patients in any of the datasets examined (data not shown), suggesting that PTTG1 is unlikely to transcriptionally downregulate p53 expression in plasma cells from MM patients. Additionally, our data suggests that PTTG1 upregulation in MM patients is not a consequence of deletion of the p53 locus 17p13, or associated TP53 mutations [71], which is observed in approximately $10 \%$ of patients and is itself associated with poor prognosis [72-74].

In addition to cell cycle genes, we found that expression of DEPDC1 (Dishevelled, EGL-10, Pleckstrin domain containing 1) was significantly up-regulated in PTTG1 high patients. Importantly, Pttg1 knockdown in myeloma cells leads to a $40 \%$ reduction in DEPDC1 expression. While the function of DEPDC1 is unknown, its expression has been associated with poor prognosis in lung cancer [75] and advanced disease in breast cancer [76]. Knockdown of DEPDC1 or inhibition using a specific peptide results in decreased cell proliferation and apoptosis in bladder cancer cell lines [77, 78]. In myeloma, $D E P D C 1$ expression has been associated with poor prognosis [29]. In addition, shRNA-mediated DEPCD1 knockdown in human myeloma cell lines was shown to significantly inhibit cell proliferation and induce accumulation in G2/M in TP53 wild-type cells and marked apoptosis in TP53 mutant cells [29]. These data suggest that regulation of $D E P D C 1$ expression may be a mechanism whereby PTTG1 regulates cell proliferation in myeloma.

Although studies have identified a role for PTTG1 in regulating epithelial-mesenchymal transition (EMT) [79-81] and recent studies by Azab and colleagues [82] have identified a role for the EMT processes in the dissemination and homing of MM plasma cells to the BM, we showed no association between the expression of 
EMT-related genes and high PTTG1 expression in MM patients. In addition, PTTG1 has previously been shown to directly mediate pro-angiogenic pathways through regulation of secreted factors VEGF and FGF-2 $[19,83,84]$, which in turn are commonly expressed in MM and associated with increased disease severity [85-87]. However, our analyses did not identify an increase in these, or other, secreted pro-angiogenic factors in the presence of increased PTTG1 expression in MM patients. These data suggest that PTTG1 is unlikely to function through EMT or angiogenic pathways in modulating MM disease.

\section{Conclusions}

In summary, we have identified PTTG1 as a gene which is over-expressed in the MM-susceptible KalwRij mouse and in MM patients with hyperdiploidy or with hyperproliferative disease, suggesting a role in MM disease development. Knockdown of Pttg1 significantly inhibited the proliferation of myeloma cells in vitro, with an associated decrease in the expression of mitosis-related genes, and slowed tumour development in vivo. While expression of PTTG1 has previously been noted in gene expression signatures defining myeloma patients with highly proliferative disease [4] and chromosomal instability [35] and, by association, poor outcomes, this is the first study to show that PTTG1 expression alone is sufficient to identify a subset of patients with poor overall survival. Collectively, our data suggest that the poor prognosis associated with PTTG1 expression is due to a hyperproliferative state in these patients, which may result from the PTTG1-mediated upregulation of key drivers of cell cycle progression.

\section{Materials and methods}

Mouse tissue and plasma cell isolation

C57BL/6 mice were obtained from the Animal Resources Centre (Perth, Australia). C57BL/KaLwRij mice, originally kindly provided by Prof. Andrew Spencer (Monash University, Melbourne, Australia), were bred and housed at the SA Pathology Animal Care Facility (Adelaide, Australia). Tissues from C57BL/6 and C57BL/ KaLwRij mice were snap frozen in liquid nitrogen and homogenised in TRIzol (Life Technologies, Carlsbad, CA). Blood was obtained from mice by cardiac puncture, collected in microfuge tubes containing $50 \mu \mathrm{L} 0.5 \mathrm{M}$ EDTA and centrifuged for $10 \mathrm{~min}$ at $500 \mathrm{~g}$ and the cell pellet resuspended in TRIzol by vigorous vortexing. Femora and tibiae from age- and sex-matched C57BL/6 and $\mathrm{C} 57 \mathrm{BL} / \mathrm{KaLwRij}$ mice were extracted and cleaned thoroughly. A 21-gauge needle was inserted into the BM cavity, and the BM was flushed with ice-cold PFE (PBS/ $2 \% \mathrm{FCS} / 2 \mathrm{mM}$ EDTA). The resulting cell suspension was subjected to Ficoll density gradient separation and collected in $10 \mathrm{~mL}$ PFE, followed by centrifugation at $300 \mathrm{~g}$ for $5 \mathrm{~min}$ at $4{ }^{\circ} \mathrm{C}$. BM cells were immediately lysed in TRIzol, or $\mathrm{CD} 138^{+}$plasma cells were isolated by FACS. Briefly, cells were resuspended at $1 \times 10^{7}$ cells $/ \mathrm{mL}$ in PFE and blocked with $110 \mu \mathrm{g} / \mathrm{mL}$ murine gamma globulin (Jackson Laboratories, Bar Harbor, ME) for $30 \mathrm{~min}$ at $4{ }^{\circ} \mathrm{C}$. Cells were stained for $30 \mathrm{~min}$ at $4{ }^{\circ} \mathrm{C}$ protected from light with rat anti-mouse CD138 ( $\mathrm{R}$ \& D Systems, Minneapolis, MN) or an isotype control, washed twice with PFE and stained with secondary goat anti-rat IgG PE (Southern Biotech, Birmingham, AL) for $30 \mathrm{~min}$ at $4{ }^{\circ} \mathrm{C}$ protected from light. Cells were washed three times with PFE, followed by sorting for $\mathrm{CD}_{138^{+}}$cells on a FACSAria II (BD Biosciences, San Jose, CA). Total RNA was isolated from sorted cells using an RNAqueous Micro kit (Life Technologies).

\section{Microarray analysis}

For comparison of PTTG1 expression in CD138+ BM plasma cells, isolated by CD138-MACS, from newly diagnosed MM or MGUS patients or normal controls, three independent datasets were used: E-GEOD-6477 (normal, $n=5$; MGUS, $n=11$; MM, $n=133$ [61]), E-GEOD-16122 (normal, $n=15$; MGUS, $n=22$; MM, $n=73$ [88]) and EMTAB-363 (normal, $n=5$; MGUS, $n=5$; MM, $n=156$ [89]). Analysis of PTTG1 expression in different gene expression-defined (UAMS) patient subsets was conducted in GSE4581 $(n=414)$ [4]. Analysis of patient survival in PTTG1 high and PTTG1 low newly diagnosed MM patients was carried out using GSE4581 analysing patients included in the total therapy 2 (TT2) trial $(n=256)$. Four independent datasets were used for analysis of gene expression in PTTG1 high (quartile 4) and PTTG1 low (quartiles 1-3) patient subsets in CD138-selected BM plasma cells from newly diagnosed MM patients: EGEOD-19784 $(n=328)$ [90], E-GEOD-26863 $(n=304)$ [91], E-MTAB-317 $(n=226)$ [45] and E-MTAB-363 $(n=$ 156). E-MTAB-363, E-GEOD-26863, E-MTAB-317 and GSE4581 were conducted on Affymetrix GeneChip Human Genome U133 plus 2.0 arrays; E-GEOD-6477 and EGEOD-16122 were conducted on Affymetrix GeneChip Human Genome U133A arrays. For all datasets except GSE4581, raw microarray data (CEL files) were downloaded from ArrayExpress (EMBL-EBI) and were normalised by RMA using the bioconductor package (affy) [92] and $R$ (version 3.03) and $\log _{2}$ transformed. One patient in E-MTAB-363 (V0681) failed quality control (normalised unscaled standard error [NUSE] >1.05) and was excluded, and the remaining 165 files were re-normalised. For GSE4581, MAS5-normalised data were downloaded from the Gene Expression Omnibus (GEO) and were $\log _{2}$ normalised prior to analysis. GO annotation (http://www.geneontology.org) and DAVID [93, 94] were used to classify genes by related function. 


\section{MM patient samples}

BM trephines and aspirates were collected, with informed consent, from patients with $\mathrm{MM}$ at the time of diagnosis and prior to initiation of therapy. This study was approved by the Royal Adelaide Hospital Human Research Ethics Committee (application \# RAH 030206 and 131133).

\section{CD138 ${ }^{+}$plasma cell isolation from MM patients}

$\mathrm{CD} 138^{+}$plasma cells were isolated from diagnostic MM patient BM samples using CD138 microbeads (Miltenyi Biotech, Auburn, CA) as previously described [15]. Briefly, cryopreserved human BM samples were thawed into $10 \mathrm{~mL}$ DMEM (high glucose) with $15 \% \mathrm{FCS}$ and DNase I $(80 \mathrm{U} / \mathrm{mL})$. Samples were centrifuged at $300 g$ for $10 \mathrm{~min}$ and supernatant removed. The cell pellet was resuspended in MACS buffer (2 mM EDTA, $0.5 \%$ deionised BSA in PBS) and CD138 microbeads added, followed by incubation on ice for $15 \mathrm{~min}$. Cell-bead conjugates were washed in $1 \mathrm{~mL}$ MACS buffer and centrifuged at $300 \mathrm{~g}$ for $10 \mathrm{~min}$. Cells were resuspended in MACS buffer, applied to a pre-rinsed MS column and washed three times with MACS buffer and eluted in $1 \mathrm{~mL}$. Subsequent FACS analysis confirmed $>85 \% \mathrm{CD} 138^{+}$following MACS. Total RNA was isolated using an All Prep DNA/RNA Micro Kit (Qiagen, Valencia, CA).

\section{Dual colour staining BM trephines}

Paraffin-embedded BM trephine sections were mounted on silicane-coated slides and dried. Endogenous peroxidase was blocked with $0.5 \% \mathrm{H}_{2} \mathrm{O}_{2}$ in methanol at room temperature for $30 \mathrm{~min}$, followed by blocking with $3 \%$ normal horse serum (NHS) for $30 \mathrm{~min}$. Slides were incubated with anti-PTTG1 antibody (diluted 1:50; DCS-280; Abcam) at room temperature overnight. Slides were washed twice in PBS and incubated with biotinylated anti-mouse IgG (Vector Laboratories, Burlingame, CA) diluted 1:250 for $30 \mathrm{~min}$ at room temperature, washed in PBS and incubated with streptavidin Alexa Fluor 488 (diluted 1:500; Life Technologies) diluted 1:500 for $1 \mathrm{~h}$ at room temperature. Slides were re-blocked with $3 \%$ NHS for $30 \mathrm{~min}$ and incubated with mouse anti-human CD138 (diluted 1:40; MI15, Dako, Denmark) overnight. Slides were washed twice with PBS followed by incubation for $1 \mathrm{~h}$ at room temperature with anti-mouse Alexa Fluor 594 (diluted 1:500, Life Technologies) and mounted in aqueous mounting solution. Images were taken on a Zeiss LSM 700 confocal system (Zeiss, Oberkocken, Germany) at $\times 40$ magnification.

\section{Cell lines}

The murine myeloma plasma cell line 5TGM1 was kindly provided by Ass. Prof. Claire Edwards (University of Oxford, Oxford, UK), and was maintained in Iscove's modified Dulbecco's medium (Sigma) with $20 \%$ FCS. Unless otherwise specified, all culture medium was supplemented with $2 \mathrm{mM}$ L-glutamine, $100 \mathrm{U} / \mathrm{mL}$ penicillin, $100 \mu \mathrm{g} / \mathrm{mL}$ streptomycin, $10 \mathrm{mM}$ HEPES buffer (Life Technologies) and $1 \mathrm{mM}$ sodium pyruvate.

\section{Generation of stable PTTG1 knockdown lines}

To generate stable knockdown cell lines, an RNA duplex targeting murine Pttg1 (GGGAAATTGCAGGTTTCAA CG) was cloned into the pFIV-H1-mCherry vector. A scrambled sequence was used as a control. pFIV-H1mCherry was created by excising the GFP cassette from pFIV-H1-GFP (System Biosciences, Mountain View, CA) using $\mathrm{XbaI}$ and SalI and replacing it with the $m$ Cherry cassette from pMSCV-mCherry. Following lentiviral infection of 5TGM1-luc cells (expressing a dual GFP and luciferase reporter construct [16, 96, 97]), single-cell clones were generated from the top $10 \%$ GFP- and mCherry-expressing cells using preparative cell sorting and the automatic cell deposition unit on a Beckman Coulter Epics Altra HyperSort, using Expo MultiComp Software version 1.2B (Beckman Coulter, Miami, FL). Clonal 5TGM1-PTTG-kd and 5TGM1-SCRAM lines were used for subsequent in vitro and in vivo assays.

\section{Real-time PCR}

Total RNA was isolated using TRIzol (Life Technologies) as per the standard protocol (unless otherwise specified). For mouse and human $\mathrm{CD} 138^{+}$plasma cells, RNA was reverse transcribed using Sensiscript (Qiagen). For all other tissues and cell lines, RNA $(1 \mu \mathrm{g})$ was reverse transcribed with Superscript III (Life Technologies) as per the manufacturer's protocol. Real-time PCR was conducted on the Corbett Rotorgene using the following primers: human $\beta$-actin (F: 5'-TTGCTGACAGGATGCAGAAG-3' and R: 5'-AAGGGTGTAAAACGCAGCTC-3'), human PTTG1 (F: 5'-CGGCCTCAGATGAATGCGGCT3' and R: 5'-TTGATTGAAGGTCCAGACCCCAGC-3'), mouse Gapdh (F: 5'- ACCCAGAAGACTGTGGATGG-3' and R: 5'-CAGTGAGCTTCCCGTTCAG-3'), mouse $\beta$ actin (F: 5'-TTG CTGACAGGATGCAGAAG-3' and R: 5'-CAGTGAGCTTCCCGTTCA-3'), mouse Pttg1 (F: 5'GCTCCTGATGATGCCTACCC-3' and R: 5'-CGCCATTCAAGGGGAGAAGT-3'), mouse Ccnb1 (F: 5'-GATGAT GGGGCTGACCCAAA-3' and R: 5'-ACATGGTCTCCT GAAGCAGC-3'), mouse Cdk1 (F: 5'-GTCCGTCGTAA CCTGTTGAG-3' and R: 5'-TGACTATATTTGGATGTC GAAG-3') [98], mouse Rrm2 (F: 5'-GATTTAGCCAAG AAGTTCAAGTTACAG-3' and R: 5'-TCACACAAGGCATAGTTTCAATAGC-3') [99], mouse Birc5 (F: 5'-GAA CCCGATGACAACCCGAT-3' and R: 5'-TGGTCTCCTT TGCAATTTTGTTCT-3') and mouse Depcd1 (F: 5'-AGC TGCAGTGGAGAAACATCT-3' and R: 5'-TGGTCTCCTT TGCAATTTTGTTCT-3'). Gene expression was represented 
relative to $\beta$-actin or Gapdh expression, calculated using the $2^{-\Delta C T}$ method.

\section{Western blot analysis}

Cells were lysed in lysis buffer (1\% NP-40, $20 \mathrm{mM}$ HEPES, $150 \mathrm{mM} \mathrm{NaCl}, 10 \%$ glycerol, $2 \mathrm{mM} \mathrm{Na}_{3} \mathrm{VO}_{4}$, $10 \mathrm{mM} \mathrm{Na}{ }_{4} \mathrm{P}_{2} \mathrm{O}_{7}, 2 \mathrm{mM} \mathrm{NaF}$ and Complete EDTA-free Protease Inhibitor Cocktail (Roche, Mannheim, Germany)). Total lysate $(10 \mu \mathrm{g})$ was loaded on an $11 \%$ acrylamide gel and subjected to SDS-PAGE. Proteins were transferred to PVDF membrane overnight. Membrane was incubated for $1 \mathrm{~h}$ in blocking buffer (Trisbuffered saline containing $0.1 \%$ Tween 20 and $2.5 \%$ ECL Blocking Agent (GE Healthcare, Little Chalfont, $\mathrm{UK})$ ) and for $2 \mathrm{~h}$ at RT with mouse monoclonal antiPTTG1 antibody (DCS-280; Abcam; Cambridge, MA) diluted 1:1000 in blocking buffer, followed by alkaline phosphate-conjugated anti-mouse IgG (Millipore, Billerica, MA) diluted 1:4000 in blocking buffer for $1 \mathrm{~h}$ at RT. Proteins were visualised using ECL detection reagent (GE Healthcare) on a Typhoon FLA 7000 IP $^{2}$ (GE Healthcare).

\section{Proliferation assays}

For WST-1 assays, 5TGM1 cells (PTTG-kd or SCRAM controls) were seeded at $1 \times 10^{5}$ cells/well in triplicate in 96-well plates and were incubated at $37{ }^{\circ} \mathrm{C}$ with $5 \%$ $\mathrm{CO}_{2}$. At 24-h intervals, WST-1 reagent (Roche) was added to the cells and incubated for $2 \mathrm{~h}$ prior to reading absorbance at $450 \mathrm{~nm}$.

For BrdU assays, 5TGM1 cells were seeded at $4 \times 10^{5}$ cells/well in triplicate in a 96-well plate. BrdU (Roche) was immediately added to the cells and incubated for $2 \mathrm{~h}$ at $37{ }^{\circ} \mathrm{C}$ with $5 \% \mathrm{CO}_{2}$. BrdU incorporation was measured using a BrdU Cell Proliferation ELISA kit (Roche) as per manufacturer's protocol and absorbance measured at $370 \mathrm{~nm}$.

For cell cycle analysis, cells were seeded at $4 \times 10^{5}$ cells/well in a six-well plate and incubated for $24 \mathrm{~h}$ at $37{ }^{\circ} \mathrm{C}$ with $5 \% \mathrm{CO}_{2}$. Cells were fixed in ice-cold $70 \%$ $(v / v)$ ethanol, washed twice in PBS and stained with propidium iodide (PI; $40 \mu \mathrm{g} / \mathrm{mL}$; Sigma) containing $20 \mu \mathrm{g} /$ $\mathrm{mL}$ RNase A (Qiagen) for $30 \mathrm{~min}$ prior to analysis on a Gallios flow cytometer (Beckman Coulter). Cell cycle distribution was analysed using FCS Express version 4.

\section{Animals}

Ethical approval for this study was obtained from the SA Pathology/Adelaide Health Service Animal Ethics Committee (application \# 136/10). C57BL/KaLwRij mice at 6-8 weeks of age were injected with $5 \times 10^{5}$ luciferaseexpressing 5TGM1-luc cells (5TGM1-SCRAM or 5TGM1-PTTG-kd) in $100-\mu l$ sterile PBS via the tail vein. At weekly intervals, mice were administered luciferin $(150 \mathrm{mg} / \mathrm{kg})$ i.p. and imaged using the Xenogen IVIS 100 bioluminescence imaging system (Caliper Life Sciences, Hopkinton, MA) until termination of the experiment at day 28, prior to the development of lethal disease (hind limb paralysis) $[16,96]$. Total tumour burden was measured as total flux (photons/second) for each animal using Living Image software (PerkinElmer, Waltham, MA), as described previously $[15,16,97,100-103]$.

\section{Statistical analyses}

Statistical analysis was performed using GraphPad Prism version 6.03 for Windows (GraphPad Software, San Diego, CA). Variance between patient groups was assessed using Kruskal-Wallis tests with Dunn's multiple comparison tests. In each of the E-GEOD-19784, E-GEOD-26863, E-MTAB-317 and E-MTAB-363 datasets, gene expression was compared in PTTG1 high and PTTG1 low patients, using $t$ tests with Bonferroni's correction for multiple testing and $p$ values from the four datasets were combined using Fisher's method. Survival curves were compared using the log-rank (Mantel-Cox) test with hazard ratios calculated using the Mantel-Haenszel calculation. In vivo data, WST-1 assays and cell cycle distribution were analysed by two-way ANOVA with Sidak's multiple comparison tests. qRT-PCR data and BrdU incorporation were compared between groups using unpaired two-tailed $t$ tests. A $p$ value of 0.05 was considered statistically significant. Unless otherwise described, all plots depict mean + SEM of three independent experiments.

\section{Additional file}

Additional file 1: Figure S1. PTTG1 expression is upregulated in MM PC. PTTG1 expression was quantitated in CD138-selected BM PC from newly diagnosed MM patients $(n=11)$ using qRT-PCR. Graph shows mean + SD of triplicates from a single experiment.

\section{Competing interests}

The authors declare that they have no competing interests.

\section{Authors' contributions}

JN performed and designed experimental work and wrote the paper; KV performed in silico analyses and experimental work and wrote the paper; $\mathrm{DH}$ performed experimental work and wrote the paper; RB, SW and KM performed experimental work; CK performed in silico analyses; AZ facilitated research and wrote the paper. All authors read and approved the final manuscript.

\section{Acknowledgements}

This research was supported by the Beat Cancer Project of the Cancer Council of South Australia (AZ). JN was supported by a Veronika Sacco Clinical Cancer Research Fellowship (Florey Medical Research Foundation, University of Adelaide); KV was supported by a Research Fellowship from the Multiple Myeloma Research Foundation; KV and CK were supported by Mary Overton Early Career Research Fellowships (Royal Adelaide Hospital).

\section{Author details}

${ }^{1}$ Myeloma Research Laboratory, Department of Physiology, School of Medicine, Faculty of Health Sciences, University of Adelaide and Cancer 
Theme, South Australian Health and Medical Research Institute (SAHMRI), Adelaide, Australia. ${ }^{2}$ SA Pathology, Adelaide, Australia. ${ }^{3}$ Leukaemia Research Group, Cancer Theme, SAHMRI, Adelaide, Australia. ${ }^{4}$ Discipline of Physiology, School of Medicine, Faculty of Health Sciences, University of Adelaide, Cancer Theme, Level 5 South, SAHMRI, PO Box 11060, Adelaide, SA 5001, Australia.

\section{Received: 27 April 2015 Accepted: 28 September 2015} Published online: 06 October 2015

\section{References}

1. Al-Farsi K. Multiple myeloma: an update. Oman Med J. 2013;28(1):3-11.

2. Landgren $\mathrm{O}$, Morgan GJ. Biologic frontiers in multiple myeloma: from biomarker identification to clinical practice. Clin Cancer Res. 2014;20(4):804-13.

3. Dzikiewicz-Krawczyk A. MicroRNA-binding site polymorphisms in hematological malignancies. J Hematol Oncol. 2014;7(1):83.

4. Zhan F, Huang Y, Colla S, Stewart JP, Hanamura I, Gupta S, et al. The molecular classification of multiple myeloma. Blood. 2006;108(6):2020-8.

5. Shaughnessy Jr JD, Zhan F, Burington BE, Huang Y, Colla S, Hanamura I, et al. A validated gene expression model of high-risk multiple myeloma is defined by deregulated expression of genes mapping to chromosome 1 . Blood. 2007;109(6):2276-84.

6. Decaux O, Lode L, Magrangeas F, Charbonnel C, Gouraud W, Jezequel P, et al. Prediction of survival in multiple myeloma based on gene expression profiles reveals cell cycle and chromosomal instability signatures in high-risk patients and hyperdiploid signatures in low-risk patients: a study of the Intergroupe Francophone du Myelome. J Clin Oncol. 2008;26(29):4798-805.

7. Kumar SK, Dispenzieri A, Lacy MQ, Gertz MA, Buadi FK, Pandey S, et al. Continued improvement in survival in multiple myeloma: changes in early mortality and outcomes in older patients. Leukemia. 2014;28(5):1122-8.

8. Radl J, Hollander CF, van den Berg P, de Glopper E. Idiopathic paraproteinaemia. I. Studies in an animal model_the ageing C57BL/KaLwRij mouse. Clin Exp Immunol. 1978;33(3):395-402.

9. Radl J, Croese JW, Zurcher C, Van den Enden-Vieveen MH, de Leeuw AM Animal model of human disease. Multiple myeloma. Am J Pathol. 1988;132(3):593-7.

10. Fowler JA, Mundy GR, Lwin ST, Lynch CC, Edwards CM. A murine model of myeloma that allows genetic manipulation of the host microenvironment. Dis Model Mech. 2009;2(11-12):604-11.

11. Garrett IR, Dallas S, Radl J, Mundy GR. A murine model of human myeloma bone disease. Bone. 1997;20(6):515-20.

12. Oyajobi BO, Munoz S, Kakonen R, Williams PJ, Gupta A, Wideman CL, et al. Detection of myeloma in skeleton of mice by whole-body optical fluorescence imaging. Mol Cancer Ther. 2007;6(6):1701-8.

13. Radl J, De Glopper ED, Schuit HR, Zurcher C. Idiopathic paraproteinemia. II. Transplantation of the paraprotein-producing clone from old to young C57BL/KaLwRij mice. J Immunol. 1979;122(2):609-13.

14. Vanderkerken K, De Raeve H, Goes E, Van Meirvenne S, Radl J, Van Riet I, et al. Organ involvement and phenotypic adhesion profile of 5T2 and 5T33 myeloma cells in the C57BL/KaLwRij mouse. Br J Cancer. 1997;76(4):451-60.

15. Noll JE, Hewett DR, Williams SA, Vandyke K, Kok C, To LB, et al. SAMSN1 is a tumor suppressor gene in multiple myeloma. Neoplasia. 2014;16(7):572-85.

16. Noll JE, Williams SA, Tong CM, Wang H, Quach JM, Purton LE, et al. Myeloma plasma cells alter the bone marrow microenvironment by stimulating the proliferation of mesenchymal stromal cells. Haematologica. 2014;99(1):163-71.

17. Fowler JA, Lwin ST, Drake MT, Edwards JR, Kyle RA, Mundy GR, et al. Host-derived adiponectin is tumor-suppressive and a novel therapeutic target for multiple myeloma and the associated bone disease. Blood. 2011;118(22):5872-82.

18. Saez C, Japon MA, Ramos-Morales F, Romero F, Segura DI, Tortolero M, et al. hpttg is over-expressed in pituitary adenomas and other primary epithelial neoplasias. Oncogene. 1999;18(39):5473-6.

19. Zhang X, Horwitz GA, Heaney AP, Nakashima M, Prezant TR, Bronstein MD, et al. Pituitary tumor transforming gene (PTTG) expression in pituitary adenomas. J Clin Endocrinol Metab. 1999:84(2):761-7.

20. Heaney AP, Singson R, McCabe CJ, Nelson V, Nakashima M, Melmed S. Expression of pituitary-tumour transforming gene in colorectal tumours. Lancet. 2000;355(9205):716-9.

21. Boelaert K, McCabe CJ, Tannahill LA, Gittoes NJ, Holder RL, Watkinson JC, et al, Pituitary tumor transforming gene and fibroblast growth factor-2 expression: potential prognostic indicators in differentiated thyroid cancer. J Clin Endocrinol Metab. 2003;88(5):2341-7.

22. Rehfeld N, Geddert H, Atamna A, Rohrbeck A, Garcia G, Kliszewski S, et al. The influence of the pituitary tumor transforming gene-1 (PTTG-1) on survival of patients with small cell lung cancer and non-small cell lung cancer. J Carcinog. 2006:5:4

23. Tfelt-Hansen J, Kanuparthi D, Chattopadhyay N. The emerging role of pituitary tumor transforming gene in tumorigenesis. Clin Med Res. 2006;4(2):130-7.

24. Chiriva-Internati M, Ferrari R, Prabhakar M, Yu Y, Baggoni L, Moreno J, et al. The pituitary tumor transforming gene 1 (PTTG-1): an immunological target for multiple myeloma. J Transl Med. 2008;6:15.

25. Wang Z, Lu QY, Chen P, Zhang P, Cong YQ. Expression of pituitary tumor-transforming gene in patients with multiple myeloma. Zhongguo Shi Yan Xue Ye Xue Za Zhi. 2006;14(6):1143-5.

26. Dominguez A, Ramos-Morales F, Romero F, Rios RM, Dreyfus F, Tortolero M, et al. hpttg, a human homologue of rat pttg, is overexpressed in hematopoietic neoplasms. Evidence for a transcriptional activation function of hPTTG. Oncogene. 1998;17(17):2187-93.

27. Asosingh K, Radl J, Van Riet I, Van Camp B, Vanderkerken K. The 5TMM series: a useful in vivo mouse model of human multiple myeloma. Hematol J. 2000;1(5):351-6.

28. Dallas SL, Garrett IR, Oyajobi BO, Dallas MR, Boyce BF, Bauss F, et al. Ibandronate reduces osteolytic lesions but not tumor burden in a murine model of myeloma bone disease. Blood. 1999;93(5):1697-706.

29. Kassambara A, Schoenhals M, Moreaux J, Veyrune JL, Reme T, Goldschmidt H, et al. Inhibition of DEPDC1A, a bad prognostic marker in multiple myeloma, delays growth and induces mature plasma cell markers in malignant plasma cells. PLoS One. 2013;8(4):e62752.

30. Kakar SS. Molecular cloning, genomic organization, and identification of the promoter for the human pituitary tumor transforming gene (PTTG). Gene. 1999;240(2):317-24.

31. Zhang X, Horwitz GA, Prezant TR, Valentini A, Nakashima M, Bronstein MD, et al. Structure, expression, and function of human pituitary tumor-transforming gene (PTTG). Mol Endocrinol. 1999;13(1):156-66.

32. Hamid T, Malik MT, Kakar SS. Ectopic expression of PTTG1/securin promotes tumorigenesis in human embryonic kidney cells. Mol Cancer. 2005:4(1):3.

33. Salehi F, Kovacs K, Scheithauer BW, Lloyd RV, Cusimano M. Pituitary tumor-transforming gene in endocrine and other neoplasms: a review and update. Endocr Relat Cancer. 2008;15(3):721-43.

34. Saez C, Pereda T, Borrero JJ, Espina A, Romero F, Tortolero M, et al. Expression of hpttg proto-oncogene in lymphoid neoplasias. Oncogene. 2002;21(53):8173-7.

35. Chung TH, Mulligan G, Fonseca R, Chng WJ. A novel measure of chromosome instability can account for prognostic difference in multiple myeloma. PLOS One 2013;8(6):e66361.

36. Bernal JA, Luna R, Espina A, Lazaro I, Ramos-Morales F, Romero F, et al. Human securin interacts with p53 and modulates p53-mediated transcriptional activity and apoptosis. Nat Genet. 2002;32(2):306-11.

37. Zou H, McGarry TJ, Bernal T, Kirschner MW. Identification of a vertebrate sister-chromatid separation inhibitor involved in transformation and tumorigenesis. Science. 1999;285(5426):418-22.

38. Kim D, Pemberton H, Stratford AL, Buelaert K, Watkinson JC, Lopes V, et al. Pituitary tumour transforming gene (PTTG) induces genetic instability in thyroid cells. Oncogene. 2005;24(30):4861-6.

39. Winnepenninckx V, Debiec-Rychter M, Belien JA, Fiten P, Michiels S, Lazar V, et al. Expression and possible role of hPTTG1/securin in cutaneous malignant melanoma. Mod Pathol. 2006;19(9):1170-80.

40. Yu R, Heaney AP, Lu W, Chen J, Melmed S. Pituitary tumor transforming gene causes aneuploidy and p53-dependent and p53-independent apoptosis. J Biol Chem. 2000;275(47):36502-5.

41. Yu R, Lu W, Chen J, McCabe CJ, Melmed S. Overexpressed pituitary tumortransforming gene causes aneuploidy in live human cells. Endocrinology. 2003;144(11):4991-8.

42. Jallepalli PV, Waizenegger IC, Bunz F, Langer S, Speicher MR, Peters JM, et al. Securin is required for chromosomal stability in human cells. Cell. 2001;105(4):445-57.

43. Mu YM, Oba K, Yanase T, Ito T, Ashida K, Goto K, et al. Human pituitary tumor transforming gene (hPTTG) inhibits human lung cancer A549 cell growth through activation of p21(WAF1/CIP1). Endocr J. 2003;50(6):771-81. 
44. Heaney AP, Nelson V, Fernando M, Horwitz G. Transforming events in thyroid tumorigenesis and their association with follicular lesions. J Clin Endocrinol Metab. 2001;86(10):5025-32.

45. Hose D, Reme T, Hielscher T, Moreaux J, Messner T, Seckinger A, et al. Proliferation is a central independent prognostic factor and target for personalized and risk-adapted treatment in multiple myeloma. Haematologica. 2011;96(1):87-95.

46. Ramos-Morales F, Dominguez A, Romero F, Luna R, Multon MC, Pintor-Toro $J A$, et al. Cell cycle regulated expression and phosphorylation of hpttg proto-oncogene product. Oncogene. 2000;19(3):403-9.

47. Filippella M, Galland F, Kujas M, Young J, Faggiano A, Lombardi G, et al. Pituitary tumour transforming gene (PTTG) expression correlates with the proliferative activity and recurrence status of pituitary adenomas: a clinical and immunohistochemical study. Clin Endocrinol (Oxf). 2006;65(4):536-43.

48. Menicanin D, Bartold PM, Zannettino AC, Gronthos S. Identification of a common gene expression signature associated with immature clonal mesenchymal cell populations derived from bone marrow and dental tissues. Stem Cells Dev. 2010;19(10):1501-10.

49. Yu R, Ren SG, Horwitz GA, Wang Z, Melmed S. Pituitary tumor transforming gene (PTTG) regulates placental JEG-3 cell division and survival: evidence from live cell imaging. Mol Endocrinol. 2000;14(8):1137-46.

50. Yu R, Cruz-Soto M, Li Calzi S, Hui H, Melmed S. Murine pituitary tumortransforming gene functions as a securin protein in insulin-secreting cells. J Endocrinol. 2006;191(1):45-53.

51. Pei L, Melmed S. Isolation and characterization of a pituitary tumortransforming gene (PTTG). Mol Endocrinol. 1997;11(4):433-41.

52. Ishitsuka Y, Kawachi Y, Taguchi S, Maruyama H, Fujisawa Y, Furuta J, et al. Pituitary tumor-transforming gene 1 enhances proliferation and suppresses early differentiation of keratinocytes. J Invest Dermatol. 2012;132(7):1775-84.

53. Chesnokova V, Kovacs K, Castro AV, Zonis S, Melmed S. Pituitary hypoplasia in Pttg-/- mice is protective for $\mathrm{Rb}+/$ - pituitary tumorigenesis. Mol Endocrinol. 2005:19(9):2371-9.

54. Cho-Rok J, Yoo J, Jang YJ, Kim S, Chu IS, Yeom Yl, et al. Adenovirus-mediated transfer of siRNA against PTTG1 inhibits liver cancer cell growth in vitro and in vivo. Hepatology. 2006;43(5):1042-52.

55. Genkai N, Homma J, Sano M, Tanaka R, Yamanaka R. Increased expression of pituitary tumor-transforming gene (PTTG)-1 is correlated with poor prognosis in glioma patients. Oncol Rep. 2006;15(6):1569-74.

56. Tfelt-Hansen J, Yano S, Bandyopadhyay S, Carroll R, Brown EM, Chattopadhyay N. Expression of pituitary tumor transforming gene (PTTG) and its binding protein in human astrocytes and astrocytoma cells: function and regulation of PTTG in U87 astrocytoma cells. Endocrinology. 2004;145(9):4222-31.

57. Rubinek T, Chesnokova V, Wolf I, Wawrowsky K, Vlotides G, Melmed S. Discordant proliferation and differentiation in pituitary tumor-transforming gene-null bone marrow stem cells. Am J Physiol Cell Physiol. 2007;293(3):C1082-92.

58. Tong $Y$, Tan $Y$, Zhou C, Melmed S. Pituitary tumor transforming gene interacts with Sp1 to modulate G1/S cell phase transition. Oncogene. 2007;26(38):5596-605.

59. Zhou C, Tong Y, Wawrowsky K, Melmed S. PTTG acts as a STAT3 target gene for colorectal cancer cell growth and motility. Oncogene. 2014;33(7):851-61.

60. Kuiper $R$, Broyl $A$, de Knegt $Y$, van Vliet $M$, van Beers $E$, van der Holt $B$, et al. A gene expression signature for high-risk multiple myeloma. Leukemia. 2012;26(11):2406-2413

61. Chng WJ, Kumar S, Vanwier S, Ahmann G, Price-Troska T, Henderson K, et al. Molecular dissection of hyperdiploid multiple myeloma by gene expression profiling. Cancer Res. 2007;67(7):2982-9.

62. Romagnoli M, Seveno C, Wuilleme-Toumi S, Amiot M, Bataille R, Minvielle S, et al. The imbalance between Survivin and Bim mediates tumour growth and correlates with poor survival in patients with multiple myeloma. Br J Haematol. 2009;145(2):180-9.

63. Bergsagel PL, Kuehl WM, Zhan F, Sawyer J, Barlogie B, Shaughnessy Jr J. Cyclin D dysregulation: an early and unifying pathogenic event in multiple myeloma. Blood. 2005;106(1):296-303.

64. Li F, Ambrosini G, Chu EY, Plescia J, Tognin S, Marchisio PC, et al. Control of apoptosis and mitotic spindle checkpoint by survivin. Nature. 1998;396(6711):580-4

65. Pines J, Hunter T. Isolation of a human cyclin cDNA: evidence for cyclin mRNA and protein regulation in the cell cycle and for interaction with p34cdc2. Cell. 1989;58(5):833-46.
66. Romagnoli M, Trichet V, David C, Clement M, Moreau P, Bataille R, et al. Significant impact of survivin on myeloma cell growth. Leukemia. 2007;21(5):1070-8.

67. Hamid T, Kakar SS. PTTG/securin activates expression of p53 and modulates its function. Mol Cancer. 2004;3:18.

68. Badie C, Bourhis J, Sobczak-Thepot J, Haddada H, Chiron M, Janicot M, et al. p53-dependent G2 arrest associated with a decrease in cyclins A2 and B1 levels in a human carcinoma cell line. Br J Cancer. 2000;82(3):642-50.

69. Taylor WR, Schonthal AH, Galante J, Stark GR. p130/E2F4 binds to and represses the cdc2 promoter in response to p53. J Biol Chem. 2001;276(3):1998-2006.

70. Hoffman WH, Biade S, Zilfou JT, Chen J, Murphy M. Transcriptional repression of the anti-apoptotic survivin gene by wild type p53. J Biol Chem. 2002;277(5):3247-57.

71. Lode L, Eveillard M, Trichet V, Soussi T, Wuilleme S, Richebourg S, et al. Mutations in TP53 are exclusively associated with del(17p) in multiple myeloma. Haematologica. 2010;95(11):1973-6.

72. Neri A, Baldini L, Trecca D, Cro L, Polli E, Maiolo AT. p53 gene mutations in multiple myeloma are associated with advanced forms of malignancy. Blood. 1993:81(1):128-35.

73. Corradini $P$, Inghirami $G$, Astolfi M, Ladetto $M$, Voena C, Ballerini $P$, et al. Inactivation of tumor suppressor genes, p53 and Rb1, in plasma cell dyscrasias. Leukemia. 1994;8(5):758-67.

74. Chang H, Qi C, Yi QL, Reece D, Stewart AK. p53 gene deletion detected by fluorescence in situ hybridization is an adverse prognostic factor for patients with multiple myeloma following autologous stem cell transplantation. Blood. 2005;105(1):358-60

75. Okayama H, Kohno T, Ishii Y, Shimada Y, Shiraishi K, Iwakawa R, et al. Identification of genes upregulated in ALK-positive and EGFR/KRAS/ALK-negative lung adenocarcinomas. Cancer Res. 2012;72(1):100-11.

76. Kretschmer C, Sterner-Kock A, Siedentopf F, Schoenegg W, Schlag PM, Kemmner W. Identification of early molecular markers for breast cancer. Mol Cancer. 2011;10(1):15.

77. Kanehira M, Harada Y, Takata R, Shuin T, Miki T, Fujioka T, et al. Involvement of upregulation of DEPDC1 (DEP domain containing 1) in bladder carcinogenesis. Oncogene. 2007;26(44):6448-55.

78. Harada Y, Kanehira M, Fujisawa Y, Takata R, Shuin T, Miki T, et al. Cell-permeable peptide DEPDC1-ZNF224 interferes with transcriptional repression and oncogenicity in bladder cancer cells. Cancer Res. 2010;70(14):5829-39.

79. Shah PP, Fong MY, Kakar SS. PTTG induces EMT through integrin alphaVbeta3focal adhesion kinase signaling in lung cancer cells. Oncogene. 2012;31(26):3124-35.

80. Shah PP, Kakar SS. Pituitary tumor transforming gene induces epithelial to mesenchymal transition by regulation of Twist, Snail, Slug, and E-cadherin. Cancer Lett. 2011;311(1):66-76.

81. Yoon CH, Kim MJ, Lee H, Kim RK, Lim EJ, Yoo KC, et al. PTTG1 oncogene promotes tumor malignancy via epithelial to mesenchymal transition and expansion of cancer stem cell population. J Biol Chem. 2012;287(23):19516-27.

82. Azab AK, Hu J, Quang P, Azab F, Pitsillides C, Awwad R, et al. Hypoxia promotes dissemination of multiple myeloma through acquisition of epithelial to mesenchymal transition-like features. Blood. 2012;119(24):5782-94.

83. Ishikawa H, Heaney AP, Yu R, Horwitz GA, Melmed S. Human pituitary tumor-transforming gene induces angiogenesis. J Clin Endocrinol Metab. 2001;86(2):867-74

84. McCabe CJ, Boelaert K, Tannahill LA, Heaney AP, Stratford AL, Khaira JS, et al. Vascular endothelial growth factor, its receptor KDR/FIk-1, and pituitary tumor transforming gene in pituitary tumors. J Clin Endocrinol Metab. 2002:87(9):4238-44.

85. Giatromanolaki A, Bai M, Margaritis D, Bourantas KL, Koukourakis MI, Sivridis E, et al. Hypoxia and activated VEGF/receptor pathway in multiple myeloma. Anticancer Res. 2010;30(7):2831-6.

86. Gupta D, Treon SP, Shima Y, Hideshima T, Podar K, Tai YT, et al. Adherence of multiple myeloma cells to bone marrow stromal cells upregulates vascular endothelial growth factor secretion: therapeutic applications. Leukemia. 2001;15(12):1950-61.

87. Sato N, Hattori Y, Wenlin D, Yamada T, Kamata T, Kakimoto T, et al. Elevated level of plasma basic fibroblast growth factor in multiple myeloma correlates with increased disease activity. Jpn J Cancer Res. 2002;93(4):459-66.

88. Agnelli L, Mosca L, Fabris S, Lionetti M, Andronache A, Kwee I, et al. A SNP microarray and FISH-based procedure to detect allelic imbalances in multiple myeloma: an integrated genomics approach reveals a wide gene dosage effect. Genes Chromosomes Cancer. 2009;48(7):603-14. 
89. Reme $T$, Hose $D$, Theillet $C$, Klein B. Modeling risk stratification in human cancer. Bioinformatics. 2013;29(9):1149-57.

90. Broyl A, Hose D, Lokhorst H, de Knegt Y, Peeters J, Jauch A, et al. Gene expression profiling for molecular classification of multiple myeloma in newly diagnosed patients. Blood. 2010;116(14):2543-53.

91. Chapman MA, Lawrence MS, Keats JJ, Cibulskis K, Sougnez C, Schinzel AC, et al. Initial genome sequencing and analysis of multiple myeloma. Nature. 2011:471(7339):467-72.

92. Gautier L, Cope L, Bolstad BM, Irizarry RA. affy-analysis of Affymetrix GeneChip data at the probe level. Bioinformatics. 2004;20(3):307-15.

93. Dennis Jr G, Sherman BT, Hosack DA, Yang J, Gao W, Lane HC, et al. DAVID: Database for Annotation, Visualization, and Integrated Discovery. Genome Biol. 2003:4(5):3.

94. da Huang W, Sherman BT, Lempicki RA. Systematic and integrative analysis of large gene lists using DAVID bioinformatics resources. Nat Protoc 2009;4(1):44-57.

95. Schweitzer KM, Vicart P, Delouis C, Paulin D, Drager AM, Langenhuijsen MM et al. Characterization of a newly established human bone marrow endothelial cell line: distinct adhesive properties for hematopoietic progenitors compared with human umbilical vein endothelial cells. Lab Invest. 1997;76(1):25-36.

96. Diamond P, Labrinidis A, Martin SK, Farrugia AN, Gronthos S, To LB, et al. Targeted disruption of the CXCL12/CXCR4 axis inhibits osteolysis in a murine model of myeloma-associated bone loss. J Bone Miner Res. 2009;24(7):1150-61

97. Cheong CM, Chow AW, Fitter S, Hewett DR, Martin SK, Williams SA, et al. Tetraspanin 7 (TSPAN7) expression is upregulated in multiple myeloma patients and inhibits myeloma tumour development in vivo. Exp Cell Res. 2015;332(1):24-38

98. Diril MK, Ratnacaram CK, Padmakumar VC, Du T, Wasser M, Coppola V, et al. Cyclin-dependent kinase 1 (Cdk1) is essential for cell division and suppression of DNA re-replication but not for liver regeneration. Proc Natl Acad Sci U S A. 2012:109(10):3826-31.

99. Lei $W$, Feng $X H$, Deng WB, Ni H, Zhang ZR, Jia B, et al. Progesterone and DNA damage encourage uterine cell proliferation and decidualization through up-regulating ribonucleotide reductase 2 expression during early pregnancy in mice. J Biol Chem. 2012;287(19):15174-92

100. Mrozik KM, Cheong CM, Hewett D, Chow AW, Blaschuk OW, Zannettino AC et al. Therapeutic targeting of $\mathrm{N}$-cadherin is an effective treatment for multiple myeloma. Br J Haematol. 2015

101. Zinonos I, Luo KW, Labrinidis A, Liapis V, Hay S, Panagopoulos V, et al. Pharmacologic inhibition of bone resorption prevents cancer-induced osteolysis but enhances soft tissue metastasis in a mouse model of osteolytic breast cancer. Int J Oncol. 2014:45(2):532-40.

102. Martin SK, Gan ZY, Fitter S, To LB, Zannettino AC. The effect of the PI3K inhibitor BKM120 on tumour growth and osteolytic bone disease in multiple myeloma. Leuk Res. 2015;39(3):380-7.

103. Gan ZY, Fitter S, Vandyke K, To LB, Zannettino AC, Martin SK. The effect of the dual PI3K and mTOR inhibitor BEZ235 on tumour growth and osteolytic bone disease in multiple myeloma. Eur J Haematol. 2015:94(4):343-54.

\section{Submit your next manuscript to BioMed Central and take full advantage of:}

- Convenient online submission

- Thorough peer review

- No space constraints or color figure charges

- Immediate publication on acceptance

- Inclusion in PubMed, CAS, Scopus and Google Scholar

- Research which is freely available for redistribution 